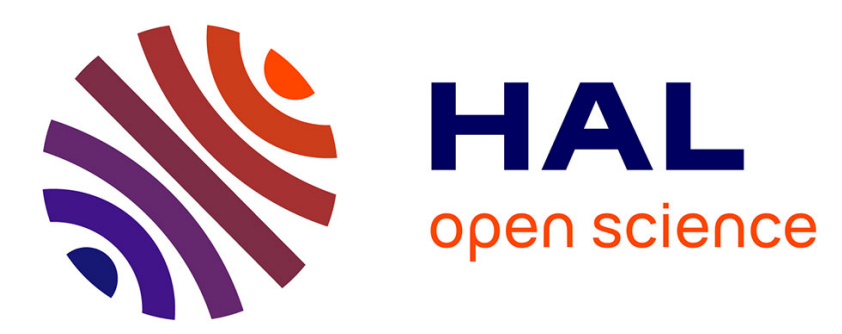

\title{
Assessment of failure criteria and damage evolution methods for composite laminates under low-velocity impact
}

Xi Li, Dayou Ma, Huifang Liu, Wei Tan, Xiaojing Gong, Chao Zhang, Yulong $\mathrm{Li}$

\section{To cite this version:}

Xi Li, Dayou Ma, Huifang Liu, Wei Tan, Xiaojing Gong, et al.. Assessment of failure criteria and damage evolution methods for composite laminates under low-velocity impact. Composite Structures, 2019, 207, pp.727-739. 10.1016/j.compstruct.2018.09.093 . hal-01997671

\section{HAL Id: hal-01997671 \\ https://hal.science/hal-01997671}

Submitted on 29 Jan 2019

HAL is a multi-disciplinary open access archive for the deposit and dissemination of scientific research documents, whether they are published or not. The documents may come from teaching and research institutions in France or abroad, or from public or private research centers.
L'archive ouverte pluridisciplinaire HAL, est destinée au dépôt et à la diffusion de documents scientifiques de niveau recherche, publiés ou non, émanant des établissements d'enseignement et de recherche français ou étrangers, des laboratoires publics ou privés. 


\title{
Assessment of failure criteria and damage evolution
}

\section{methods for composite laminates under low-velocity impact}

\author{
Xi Li ${ }^{1,2}$, Dayou Ma ${ }^{1,2}$, Huifang $\mathrm{Liu}^{1,2}$, Wei Tan ${ }^{3}$, Xiaojing Gong ${ }^{4}$, Chao Zhang ${ }^{1,2 *}$, \\ Yulong $\mathrm{Li}^{1,2^{*}}$
}

1. Department of Aeronautical Structure Engineering, School of Aeronautics, Northwestern Polytechnical University, Xi'an, Shaanxi 710072, China

2. Joint International Research Laboratory of Impact Dynamics and its Engineering Application, Xi'an, Shaanxi 710072, China

3. Engineering Department, University of Cambridge, Trumpington Street, Cambridge CB2 $1 P Z, U K$

4. Université de Toulouse, Institut Clément Ader (ICA), CNRS UMR 5312, UPS, France

\section{Abstract}

This study aims to evaluate the applicability of failure criteria and damage evolution methods in the finite element analysis of composite laminates under lowvelocity impact. Implemented by the user-defined VUMAT subroutine in ABAQUS, various progressive damage models are used to predict damage initiation and accumulation in a T700GC/M21 composite laminate. Cohesive elements are inserted between adjacent plies to capture interface delamination. The applicability of damage models is investigated by comparing the global mechanical response and distribution of various damage modes. A new variable, equivalent damage volume, is introduced to quantitatively describe the predicted damage when using different models. The numerical results establish that Hashin and Puck failure criteria generate matrix compression damage in more layers of the composite. Maximum stress and Tsai-Wu criteria are not preferred due to their improper predictions in terms of damage area and permanent deformation of the laminate. As for damage evolution laws, the equivalent strain method provides faster stiffness degradation of the laminate and a smaller area *Corresponding Author. Email: chaozhang@nwpu.edu.cn and liyulong@nwpu.edu.cn 
of matrix damage compared with the predictions of the equivalent displacement method. Keywords: Composite laminates, Failure criteria, Damage evolution, Low-velocity impact, Finite element analysis

\section{Introduction}

Composite materials, owing to various superiorities such as a high specific stiffness and strength ratio as well as design flexibility, have gradually replaced traditional metallic materials and have been applied for structures in aircraft and automobiles. However, their poor impact resistance, which is the most unfavorable characteristic of a composite material, poses a threat to the load-bearing ability of the composite following impact. With regard to dynamic impact investigations of composites, attention has gradually shifted from experimental testing to numerical simulation due to the high cost of testing and the inability to accurately monitor the damage states, especially for low-velocity impacts that can induce damage that is nearly imperceptible. Among well-developed numerical techniques, the progressive damage model (PDM) has become the most popular simulation scheme that considers initial damage detection and subsequent stiffness degradation. However, the effects of different failure criteria and damage accumulation laws on low-velocity impact prediction for composite materials have not yet been systematically investigated and need to be explored further.

Developed initially from theories proposed for isotropic materials, failure criteria for composites have experienced continuous improvement during recent decades and have been classified into two general groups: non-interactive criteria and interactive criteria [1-3]. Maximum stress and strain criteria, which do not involve shear stress and 
strain components, usually serve to estimate rarely-occurring fiber damage induced by low velocity impacts [4-7]. As for interactive criteria, the Tsai-Wu criteria [8] with polynomial equations, which were originally proposed to determine the failure surface of a composite and cannot specify damage modes, are now being applied to detect matrix damage of composites under low-velocity impact [7]. Later, interactive failure criteria based on direct-mode determining theories [1] were created with separate expressions to diagnose fiber and matrix damage under tensile and compression loading and have been used widely; these include the Hashin [9], Chang-Chang [10] and Hou $[11,12]$ criteria. To account for the strengthening effect on shear strength when a composite is subjected to transverse compression loads, Puck and Schürmann [13] subsequently modified the Hashin criteria by introducing the concept of a fracture plane for matrix damage so as to precisely describe the brittle fracture behavior.

Following damage initiation (satisfaction of failure criteria), the damaged region of a composite becomes fragile, with gradually decreasing load capacity due to a reduction in local stiffness caused by the propagation of visible or invisible cracks. Although mixed experimental-numerical approaches to simultaneously identify the stiffness of a composite laminate have been realized, the ability to detect the extent of damage and impact energy during tests are limited for published methods; moreover, the effective stiffness tensors are typically extracted from test data with inevitable simplifications, which means that improvements are still needed to facilitate wider application [14-16]. Therefore, in terms of simulating the process of damage accumulation around the damaged area, quantification techniques and theories to represent the stiffness- 
softening behaviors of composites at present are mainly empirical and semi-empirical methods that consider either instantaneous or gradual unloading [1]. For empirical methods, which correspond to different damage modes, stiffness is reduced by predefined constants. Obviously, it is difficult to verify whether or not these constants will fit the test data well. However, for semi-empirical approaches, although the determination of the extent of current damage combines mechanical parameters such as strain, stress and displacement near the damaged zone when calculating damage evolution variables, linear or exponential trends of stiffness degradation must be previously defined. Due to the involvement of mechanical parameters, methods based on fracture energy, which are typical of semi-empirical methods, are now widely employed by researchers for predicting the progressive damage behavior of composite materials [4-7,17-22].

Recently, combinations of different failure criteria and damage accumulation methods have been realized for analyzing dynamic progressive damage in composites under low-velocity impact. Zhang and Zhang [23] used Hashin criteria [9] and defined degradation constants to reduce the stiffness of the laminates. In addition, Air et al. [7] used the Tsai-Wu criteria [8], and Long et al. [18] adopted Hashin criteria [9], while Tan et al. [6] used modified Puck criteria [13] and Shi et al. [19] combined Puck's matrix compression criterion and Hashin's fiber and matrix tensile criteria in their numerical simulations; the damage evolution in all of these studies was controlled by fracture energy-based methods that involve equivalent strain. In other studies, Qiu et al. [20], Zhang et al. [21], and Caputo et al. [22] all chose Hashin criteria [9] and linear 
damage evolution methods by calculating the equivalent displacement.

World Wide Failure Exercise (WWFE) has made great contributions by evaluating different failure criteria on the theoretical level by defining test cases and conducting blind predictions of failure envelopes [24-26]. However, its conclusions for wider application under more complicated loading conditions (e.g., low-velocity impact or crush events, etc.) are still limited and detailed differences regarding the damage information are not clear. In addition, Reddy and Reddy [27] concluded that maximum stress criteria tend to over-predict failure loads for composites under axial tension, while the Tsai-Wu criteria under-predict them. Based on the analysis of laminated beams subjected to low-velocity impact in a three-point bending configuration, Santiuste et al. [28] concluded that the Hashin criteria perform better for detecting damage of ductile composites, while the Hou criteria are more suitable for brittle composites. Additionally, in a comparison to the matrix compression criterion proposed by Puck, Hashin's matrix compression failure criterion predicts more severe matrix compression damage in the upper and middle plies of laminates under low-velocity impact, as found in an investigation by Liu et al. [29]. Moreover, Farooq and Myler [30] found that failure criteria with polynomial expressions - including the Tsai-Wu [7] and Tsai-Hill criteria — cannot predict the initiation of ply failure in thick laminates due to the absence of through-thickness stresses in these failure criteria.

Hence, the main purpose of the present work is to compare the different failure criteria and damage evolution methods and to further investigate their applicability for composite laminates under low-velocity impact. First, the maximum stress criteria, 
Tsai-Wu [8], Hashin [9], Hou [11,12] and Puck [13] criteria, combined with linear degradation models, are integrated and implemented using the VUMAT subroutine in ABAQUS and are validated against the experimental results reported by Hongkarnjanakul et al. [5]. The effects of different failure criteria and damage evolution methods on global mechanical response and local damage predictions for laminates are then discussed in detail.

\section{Composite damage model}

\subsection{Damage model for a lamina}

\subsubsection{Transversely isotropic constitutive equations}

For a composite laminate, each lamina is generally treated as a transversely isotropic material, for which a transversely isotropic constitutive equation with five independent constants is employed for the undamaged lamina. By introducing different damage variables to account for deterioration of the material during subsequent loading, modified constitutive equations can be used to describe the damaged stress-strain relationship of the lamina. In this work, the degraded compliance matrix $S_{d}$ is represented as

$$
S_{d}=\left[\begin{array}{cccccc}
\frac{1}{d_{f} E_{11}} & -\frac{v_{21}}{E_{22}} & -\frac{v_{31}}{E_{33}} & & & \\
-\frac{v_{12}}{E_{11}} & \frac{1}{d_{m} E_{22}} & -\frac{v_{32}}{E_{33}} & & & \\
-\frac{v_{13}}{E_{11}} & -\frac{v_{23}}{E_{22}} & \frac{1}{E_{33}} & & & \\
& & & \frac{1}{d_{f} d_{m} G_{12}} & & \\
& & & & \frac{1}{d_{f} d_{m} G_{23}} & \\
& & & & & \frac{1}{d_{f} d_{m} G_{31}}
\end{array}\right]
$$

where $d_{f}$ and $d_{m}$ denote the fiber and matrix damage variables, respectively. Meanwhile, 
the corresponding degraded stiffness matrix $C_{d}$ can be expressed as

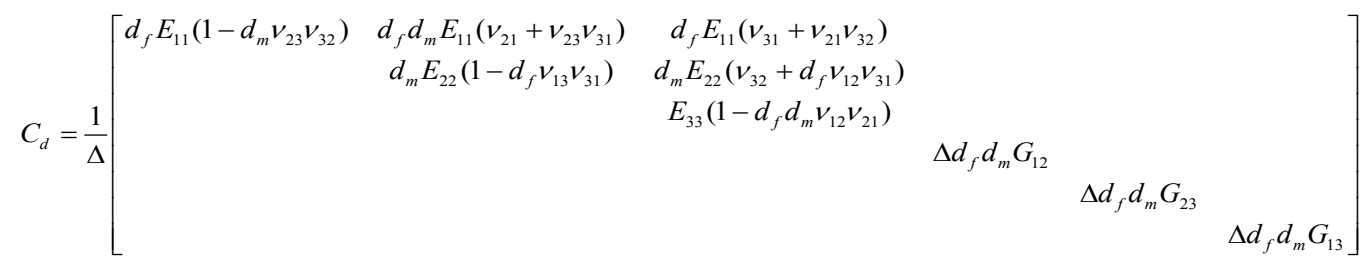

with

$$
\left\{\begin{array}{l}
d_{f}=\left(1-d_{f t}\right)\left(1-d_{f c}\right) \\
d_{m}=\max \left(\left(1-S_{m t} d_{m t}\right)^{2},\left(1-S_{m c} d_{m c}\right)^{2}\right) \\
\Delta=1-d_{f} d_{m} v_{12} v_{21}-d_{m} v_{23} v_{32}-d_{f} v_{13} v_{31}-2 d_{f} d_{m} v_{21} v_{32} v_{13}
\end{array}\right.
$$

where $d_{f t}, d_{f c}, d_{m t}$ and $d_{m c}$ are the damage variables for fiber and matrix damage under tensile and compression loads that were obtained using damage evolution methods. In addition, the coefficients $S_{m t}$ and $S_{m c}$ are introduced to eliminate element distortion due to shear stiffness degradation; their values are postulated as 0.9 and 0.5 , respectively [29,31]. The newly-proposed form of $d_{m}$ in this paper can compensate for the underestimation of damage evolution that results when the plastic deformation of the matrix is disregarded.

\subsubsection{Damage initiation criteria}

\subsubsection{Fiber damage}

Maximum stress criteria are adopted to predict fiber tensile and compression damage, as shown in Eq. (1). Here, $X_{T}$ and $X_{C}$ are the tensile strength and compression strength along the fiber orientations, respectively.

$$
r_{f t}=\left(\frac{\sigma_{11}}{X_{T}}\right)^{2}\left(\sigma_{11}>0\right), \quad r_{f c}=\left(\frac{\sigma_{11}}{X_{C}}\right)^{2}\left(\sigma_{11}<0\right)
$$

where $r_{f t}$ and $r_{f c}$ are failure criteria values for fiber tensile damage and compression damage, respectively. 


\subsubsection{Matrix damage}

As for the matrix failure criteria, the following five kinds of formulae are considered in this study: $Y_{T}$ and $Y_{C}$ are the tensile and compression strength perpendicular to fiber orientations, respectively; and $S_{12}, S_{13}$, and $S_{23}$ represent the inplane and out-of-plane shear strength.

(1) Maximum stress criterion

$$
r_{m t}=\left(\frac{\sigma_{22}}{Y_{T}}\right)^{2}\left(\sigma_{22}>0\right), \quad r_{m c}=\left(\frac{\sigma_{22}}{Y_{C}}\right)^{2}\left(\sigma_{22}<0\right)
$$

(2) Tsai-Wu criterion

$$
\left\{\begin{array}{l}
r_{m}=F_{1} \sigma_{11}+F_{2} \sigma_{22}+F_{11} \sigma_{11}^{2}+F_{22} \sigma_{22}^{2}+F_{66} \sigma_{12}^{2}+2 F_{12} \sigma_{11} \sigma_{22} \\
F_{1}=\frac{1}{X_{T}}+\frac{1}{X_{C}}, F_{11}=\frac{1}{X_{T} X_{C}}, F_{2}=\frac{1}{Y_{T}}+\frac{1}{Y_{C}}, F_{22}=\frac{1}{Y_{T} Y_{C}}, F_{66}=\frac{1}{S_{12}^{2}}
\end{array}\right.
$$

(3) Hashin criterion

$$
\left\{\begin{array}{l}
r_{m t}=\frac{1}{Y_{T}^{2}}\left(\sigma_{22}+\sigma_{33}\right)^{2}+\frac{1}{S_{23}^{2}}\left(\sigma_{23}^{2}-\sigma_{22} \sigma_{33}\right)^{2}+\frac{1}{S_{12}^{2}}\left(\sigma_{12}^{2}+\sigma_{13}^{2}\right)^{2},\left(\sigma_{22}+\sigma_{33}>0\right) \\
r_{m c}=\frac{1}{Y_{C}}\left[\left(\frac{Y_{C}}{2 S_{23}}\right)^{2}-1\right]\left(\sigma_{22}+\sigma_{33}\right)+\frac{1}{4 S_{23}^{2}}\left(\sigma_{22}+\sigma_{33}\right)^{2}+\frac{1}{S_{23}^{2}}\left(\sigma_{12}^{2}-\sigma_{22} \sigma_{33}\right)+\frac{1}{S_{12}^{2}}\left(\sigma_{12}^{2}+\sigma_{13}^{2}\right),\left(\sigma_{22}+\sigma_{33}<0\right)
\end{array}\right.
$$

(4) Hou criterion

$$
\left\{\begin{array}{l}
r_{m t}=\left(\frac{\sigma_{22}}{Y_{T}}\right)^{2}+\left(\frac{\sigma_{12}}{S_{12}}\right)^{2}+\left(\frac{\sigma_{23}}{S_{23}}\right)^{2},\left(\sigma_{22}>0\right) \\
r_{m c}=\frac{1}{4}\left(\frac{-\sigma_{22}}{S_{12}}\right)^{2}+\frac{Y_{C}^{2} \sigma_{22}}{4 S_{12}^{2} Y_{C}}-\frac{\sigma_{22}}{Y_{C}}+\left(\frac{\sigma_{12}}{S_{12}}\right)^{2},\left(\sigma_{22}<0\right)
\end{array}\right.
$$

(5) Puck criterion

$$
\left\{\begin{array}{l}
r_{m t}=\left(\frac{\sigma_{n n}}{Y_{T}}\right)^{2}+\left(\frac{\sigma_{n l}}{S_{23}^{A}}\right)^{2}+\left(\frac{\sigma_{n t}}{S_{12}}\right)^{2},\left(\sigma_{n n}>0\right) \\
r_{m c}=\left(\frac{\sigma_{n t}}{S_{23}^{A}-\mu_{n t} \sigma_{n n}}\right)^{2}+\left(\frac{\sigma_{n l}}{S_{12}-\mu_{n l} \sigma_{n n}}\right)^{2},\left(\sigma_{n n}<0\right)
\end{array}\right.
$$

where $r_{m t}$ and $r_{m c}$ are the failure criterion values for matrix tensile and compression 
damage; $r_{m}$ is the Tsai-Wu criterion value; $\sigma_{n n}, \sigma_{n l}$ and $\sigma_{n t}$ are stresses along the normal, longitudinal shear and transverse shear directions of the fracture plane, respectively, as calculated using Eq. (10); and $\theta$ is the fracture angle, which is approximately $53^{\circ}$ for a unidirectional composite under uniaxial transverse compressive load as found by Donadon et al. [32]. In addition, $S_{23}^{A}$ is the out-of-fracture-plane shear strength; $\mu_{n l}$ and $\mu_{n t}$, which are friction coefficients based on Mohr-Coloumb failure theory, are calculated using Eq. (10).

$$
\left\{\begin{array}{l}
\sigma_{n n}=\sigma_{22} \cos ^{2} \theta+\sigma_{33} \sin ^{2} \theta+2 \sigma_{23} \cos \theta \sin \theta \\
\sigma_{n l}=\sigma_{12} \cos \theta+\sigma_{13} \sin \theta \\
\sigma_{n t}=-\sigma_{22} \cos \theta \sin \theta+\sigma_{33} \cos \theta \sin \theta+2 \sigma_{23}\left(2 \cos ^{2} \theta-1\right) \\
\mu_{n t}=\tan \left(2 \theta-90^{\circ}\right), \frac{\mu_{n t}}{S_{23}^{A}}=\frac{\mu_{n l}}{S_{12}}, S_{23}^{A}=\frac{Y_{C}}{2}\left(\frac{1-\sin \phi}{\cos \phi}\right), \phi=2 \theta-90^{\circ}
\end{array}\right.
$$

A summary of the obvious differences among the failure criteria mentioned above is provided in Table 1.

\subsubsection{Damage evolution methods}

Fracture energy-based damage evolution methods with linear degradation trends are often classified into two broad types, equivalent strain or equivalent displacement, which are introduced separately below. In the equations below, $i$ represents the damage mode and $j$ denotes the longitudinal or transverse direction of the laminate.

\subsubsection{Equivalent strain method}

$$
d_{i}=\frac{\varepsilon_{e q, i}^{f}\left(\varepsilon_{e q, i}-\varepsilon_{e q, i}^{0}\right)}{\varepsilon_{e q, i}\left(\varepsilon_{e q, i}^{f}-\varepsilon_{e q, i}^{0}\right)}
$$

with $\varepsilon_{e q, i}^{0}=X_{i} / E_{0, j}, \varepsilon_{e q, i}^{f}=2 G_{i} /\left(X_{i} l_{c}\right)$, where $\varepsilon_{e q, i}^{0}$ and $\varepsilon_{e q, i}^{f}$ represent the initial and final failure strain, respectively; $X_{i}$ is the fiber or matrix strength; $E_{0, j}$ is the initial modulus of the composite lamina in the corresponding direction; $G_{i}$ is the critical fracture energy 
for the specific damage mode; and $l_{c}$ is the characteristic length of the element, which is introduced to eliminate the mesh sensitivity. In the present study, $l_{c}$, is considered to be equal to the cube root of the element volume.

\subsubsection{Equivalent displacement method}

The equivalent displacement method can be described by the following equation.

$$
d_{i}=\frac{\delta_{e q, i}^{f}\left(\delta_{e q, i}-\delta_{e q, i}^{0}\right)}{\delta_{e q, i}\left(\delta_{e q, i}^{f}-\delta_{e q, i}^{0}\right)}
$$

in which $\delta_{e q, i}^{0}=\delta_{e q, i} / \sqrt{r_{i}}$ and $\delta_{e q, i}^{f}=2 G_{i} / \sigma_{e q, i}^{0}$, where $\delta_{e q, i}^{0}$ and $\delta_{e q, i}^{f}$ denote the initial and fully damaged equivalent displacements, respectively; $r_{i}$ is the value of the corresponding failure criterion; $G_{i}$ is the critical fracture energy for the specific damage mode, the same as in Eq. (11); and $\sigma 0 e q,{ }_{i}$ is the equivalent stress at the instant of damage initiation. Detailed expressions for calculating the equivalent displacement and equivalent stress for each failure mode can be found in Zhang et al. [33].

\subsection{Damage model for the interface}

The built-in cohesive elements in ABAQUS based on a bilinear traction-separation relationship are employed to simulate delamination at the interface. Both the quadratic failure criterion and the Benzeggagh and Kenane (B-K) criterion [34], which are governed by mixed-mode fracture energy laws, are used to predict the initiation and propagation of delamination damage, as expressed in Eq. (13) and Eq. (14), respectively.

$$
\frac{\left\langle t_{n}\right\rangle^{2}}{N^{2}}+\frac{t_{s}^{2}}{S^{2}}+\frac{t_{t}^{2}}{S^{2}}=1
$$

where $t_{n}, t_{s}$ and $t_{t}$ are normal and shear tractions; $N$ and $S$ are interface normal strength and shear strength, respectively; and the Macaulay bracket signifies that compressive 
deformation is excluded.

$$
G_{n}^{C}+\left(G_{s}^{C}-G_{n}^{C}\right)\left\{\frac{G_{S}}{G_{T}}\right\}^{\eta}=G^{C}
$$

where $G_{n}^{C}$ and $G_{S}^{C}$ are the critical normal and shear fracture energy, respectively; $G_{S}$ is the amount of dissipated energy in the out-of-plane shear directions; and $G_{T}$ is the total dissipated energy for all three directions; and where the relevant material coefficient $\eta$ involved in the B-K formula is set as 1.45 .

\section{Finite element model}

A T700CG/M21 carbon/epoxy composite laminate with stacking sequences of $\left[\mathrm{O}_{2}\right.$, $\left.45_{2}, 90_{2},-45_{2}\right]$ and a geometry size of $100 \times 150 \times 4 \mathrm{~mm}$ is adopted here for the numerical analysis; detailed material properties for this composite are listed in Table 2. To improve computational efficiency, every two adjacent plies having the same ply orientation are treated as a single layer and are meshed in ABAQUS/Explicit using C3D8R, an eight-node linear brick, reduced integration element. The relax stiffness hourglass-control method is chosen to reduce zero-energy modes in the ABAQUS/Explicit simulations. In addition, cohesive interfaces with a thickness of 1e-3 $\mathrm{mm}$ are modeled with $\mathrm{COH} 3 \mathrm{D} 8$, an eight-node three dimensional elements and are inserted between adjacent plies to simulate delamination damage. In this numerical model, element deletion is not allowed in view that no penetration was observed during the low-velocity impact tests reported by Hongkarnjanakul et al. [5]. The central area with a size of $60 \times 40 \mathrm{~mm}$ is meshed with an element size of $1.2 \times 1 \times 0.5 \mathrm{~mm}$, and the inplane mesh size becomes gradually coarser with increasing distance from the target domain. The total number of elements for the discretized plate is 82889 . The steel 
impactor is considered as a discrete rigid body with a lumped reference mass of $2 \mathrm{~kg}$ and is meshed with R3D4 (four-node 3D bilinear rigid quadrilateral) elements. The diameter is $16 \mathrm{~mm}$ and velocity is $5 \mathrm{~m} / \mathrm{s}$, which depends on the impact energy (25 J).

For the drop test published by Hongkarnjanakul et al. [5], the rectangular composite plate is supported along all four edges, leaving an inner region of $75 \times 125 \mathrm{~mm}$. The four corners of the plate are clamped so as to prevent large out-of-plane movement of the specimen. In the present study, a rigid supporter with all directions restrained, as shown in Fig. 1, is placed below the plate, which was adopted by some researchers [5, 6, 29]. Displacement in the $Z$-axis direction of selected nodes around the four corners of the plate is also constrained to simulate the constraints of the four rubber clamps in the test fixture. In addition, given that the impactor could not penetrate the composite plate entirely in a low-velocity impact, a general contact algorithm in ABAQUS/Explicit is adopted to simulate contact between the impactor, the composite laminate and the support as well as ply-to-ply contact in the laminate. Hard contact and the penalty method with a friction coefficient generally set as 0.3 are employed to describe the normal and tangential contact behaviors, respectively. The total simulation period lasts $4 \mathrm{~ms}$, and the stable incremental time is set to below $1 \mathrm{e}-4 \mathrm{~ms}$ to achieve numerical convergence.

\section{Numerical results and discussion}

\subsection{Validation of the established damage model}

To demonstrate the proper setup of the finite element model, the numerical results for a representative model with Hou's failure criterion and a displacement-based 
damage evolution model was selected for comparison with experimental results for a T700CG/M21 composite from Hongkarnjanakul et al. [5]. As shown in Fig. 2(a) and 2(b), the numerical predicted force-time and force-displacement curves match with the experimental results reasonably well, despite some deviations that were probably produced by the immeasurable clamp force on the four corners of the laminate during testing. Moreover, the predicted distribution of delamination damage correlates well with the experimental data, showing a slightly larger area for the top interface near the impact side.

During the numerical simulation, at around $t=0.18 \mathrm{~ms}$, which is approximately $0.05 \mathrm{~ms}$ later than in the experiments, the contact force shows a slight tendency to decline until $t=0.35 \mathrm{~ms}$. During this period, no matrix compression damage is initiated on the impact side, while obvious expansion occurs in regions of matrix tensile and delamination damage. Afterwards, both the experimental and the numerical contact forces show a decreasing trend in the growth rate from $t=0.35 \mathrm{~ms}$ to $t=1 \mathrm{~ms}$, accompanied by a remarkable degradation in stiffness. Followed by a further increase in force and a reduction in stiffness, the impactor reaches the lowest position and rebounds at $t=1.6 \mathrm{~ms}$, which is consistent with test observations. Meanwhile, the outof-plane displacement of the laminate recovers gradually, and the matrix and interface damage continue to propagate for a certain time. Overall, the computational algorithm realized by the VUMAT subroutine and the low-velocity impact model is considered to be validated, with a capability to predict well the dynamic progressive damage of a composite laminate under low-velocity impact. 


\subsection{Evaluation of failure criteria}

For the purpose of analyzing the effect of different failure criteria on the global mechanical response and local damage of the laminate, the fiber failure formula and damage evolution model are fixed at the maximum stress criterion, and the equivalent displacement method is adopted. It is assumed that the fiber failure criteria do not affect the numerical predictions to a great extent, as fiber damage is rarely observed during a low-velocity impact. Also, considering the necessity of distinguishing the damage modes for the damage evolution model, the Tsai-Wu criterion were modified to specify matrix tensile $\left(\sigma_{22}>0\right)$ and compression damage $\left(\sigma_{22}<0\right)$.

\subsubsection{Global mechanical response}

Fig. 3 exhibits force-time and force-displacement curves obtained from the experiments and the numerical simulations. Little difference was found between the numerical results of models with different matrix-damage failure criteria. This suggests that all the studied matrix failure criteria can adequately predict the global mechanical response of a laminate under low-velocity impact.

Table 3 summarizes the numerically predicted properties and their errors in comparison with the test data. For the prediction of peak force, the Hashin criterion exhibits the maximum value of the five criteria and the value is indisputably closest to the test data, while the maximum stress criterion is the next closest. Meanwhile, the Hou criterion shows the highest predicted deviations followed by the Tsai-Wu criterion. With regard to the prediction of maximum displacement, the errors for maximum stress, Tsai-Wu and Hashin criteria range between $+7 \%$ to $+8 \%$, while the error for the Hashin 
criterion is the lowest, at $+7.05 \%$. The Hou criterion and the Puck criterion both produce relatively large errors (more than $+9 \%$ ). For the prediction of contact time, the maximum stress criterion and the Hashin criterion both present the lowest error $(+3.3 \%)$, while the Tsai-Wu criterion and the Puck criterion rank second, with an error equal to $+5.6 \%$. The Hou criterion presents the worst prediction for both maximum displacement and contact time. In terms of dissipated energy, the prediction using the Tsai-Wu criterion correlates better with the experimental value, followed by the Hou criterion. In addition, the Hashin criterion and the Puck criterion provide relatively low values of dissipated energy (10.4 J and $10.62 \mathrm{~J}$, respectively), while the maximum stress criterion ranks last. Overall, the errors for the predicted mechanical response for finite element models with all failure criteria are consistent in terms of positive or negative deviation. Models using the Tsai-Wu criterion and the Hou criterion are better at predicting the dissipated energy, at the cost of comparatively higher errors in predicting the peak force, maximum displacement and contact time. The results also suggest that the matrix failure behavior of composite laminates do not significantly affect the global mechanical response.

\subsubsection{Matrix tensile damage}

Fig. 4 compares the matrix tensile damage distribution in each layer of the numerical models when adopting different failure criteria. The region shown in red represents locations where elements failed completely, while blue represents undamaged regions, which is also defined for all the damage contours in this study. The matrix tensile damage of all models shows the same propagation direction: along the 
fiber orientation of each ply. Concerning the damage shape, there are obvious differences in the top four layers near the impact side for the five models that use different failure criteria. However, the shape of the damaged region in the back four layers is more or less the same. The deviation in the shape of the damaged area can be explained by the deformation and failure mechanism of the laminate, where matrix compression damage first initiates on the impact side and expands to the back side, while matrix tensile damage is induced originally on the back side and propagates to the upper layers [35]. Thus, matrix tensile damage generated near the impact side can be affected by the corresponding distribution of compression damage in the matrix, which contributes to final differences in the shape of regions of tensile damage in the top four layers. On the other hand, the predicted damage contours of the model using the Hashin criterion exhibit a hollowed shape in the top four plies, which is distinct from those of the other models. This finding is attributed to the fact that the Hashin criterion uses the summation of transverse and out-of-plane normal stress to evaluate the loading status (tension or compression) for matrix-type failure, while the other criteria use only the transverse stress or the out-of-plane normal stress (see Table 1).

For a quantitative comparison, refer to Fig. 5(a), which summarizes and compares the matrix tensile damage area on a layer-by-layer basis. It should be noted that the presented area is based on elements where the matrix tensile damage variable exceeds 0.5, which can be regarded as severe damage that would make an obvious contribution to the reduction in stiffness of the laminate. As can be noticed from Fig. 5(a), it is evident that for all failure criteria, the predicted matrix tensile damage area is larger 
when the corresponding layer is farther away from the impact side. In addition, the deviations in the predicted damage area are more apparent on the impact side and the back side (the back side in particular). The predicted area of maximum stress criterion is the lowest in comparison with other criteria, because it disregards the contribution of shear stress to the tensile failure of the matrix. It was also found that the failure criterion that predicts a larger matrix tensile damage area on the impact side usually predicts less damage area on the back side - except for the maximum stress criterion, which always predicts a relatively smaller area of damage. Overall, the numerical deviations produced by different failure criteria are not evident, and the predicted damage area in all layers is nearly the same for the Hou and Puck criteria due to their use of identical formulas for the matrix tensile criteria.

\subsubsection{Matrix compression damage}

Fig. 6 shows the effect of the failure criterion on the prediction of matrix compression damage. Obviously, the deviation of matrix compression damage prediction is more significant than that of matrix tensile damage. For the majority of cases, only the upper layers near the impact side are identified with matrix compression damage, except for models using Hashin and Puck criteria, where the matrix compression damage was detected in nearly every ply. The predicted compression damage contours of the top two layers for all failure criteria are presented in Fig. 6(a). From Fig. 6(a), it is evident that the shapes for damage predicted by models with different criteria are entirely different, except for the similar damage pattern in the top layer predicted by models using the Hou and Hashin criteria. Compared with Hashin 
criterion, the fewer damaged layers predicted by the Hou criterion are due to the specific judgment of matrix tensile and compression damage in the Hashin criterion, and the absence of normal stress components $\left(\sigma_{33}\right)$ along the thickness direction in the Hou criterion. Fig. 6(b) shows the predicted results for matrix compression damage in the remaining layers for the Hashin and Puck criteria, where the damage mainly concentrates on the impact point and seldom propagates in other directions.

Fig. 5(b) summarizes and compares the predicted areas of matrix compression damage. In contrast to the matrix tensile damage (Fig. 5(a)), the area of matrix compression damage decreases gradually from the impact side to the bottom layer. Moreover, the areas of predicted damage on the impact side are remarkably distinct when using different criteria. The areas of predicted damage when using the Hashin, Hou, and Puck criteria are all greater than $100 \mathrm{~mm}^{2}$, while the areas are around $50 \mathrm{~mm}^{2}$ for the maximum stress and Tsai-Wu criteria. Although these apparent differences in estimates of matrix compression damage cannot create much derivation in the prediction of the global mechanical response, uncertainty and risk still exist for subsequent unpredictable loading during the real serve life of a composite structure if the predicted matrix compression damage area presents such a large variation. Therefore, further judgments assisted by damage detection technologies need to be proposed to identify experimental matrix compression damage behavior during an impact test. In the present study, the matrix compression damage area predicted by the Hashin criterion is larger than that predicted by the Puck criterion, which is also in agreement with the numerical results reported by Liu et al. [29]. From the perspective 
of engineering applications, the matrix compression failure formula proposed by Hashin is regarded as a better choice due to its extremely conservative prediction (more damaged layers and a larger area of damage in each ply) and its easily-understandable mathematical expression in comparison with Puck's criterion.

\subsubsection{Interface delamination}

Fig. 7 illustrates the influence of failure criteria on the prediction of delamination damage contours for each interface layer. First, for the top four interfaces, the predicted delamination area and damage propagation behavior are similar for all models considered. The damage propagation direction is parallel with the fiber orientations of the lamina below the corresponding interface, which is consistent with the conclusions of Liu et al. [29]. However, the distribution of delamination damage in the bottom three layers is more complicated and does not match the aforementioned distribution regulations. Similar to the prediction of matrix damage, the failure criteria selection affects the delamination prediction more for the top and bottom interfaces than for the interfaces between the intermediate layers. Fig. 5(c) compares the prediction results of delamination area in each layer for the five different failure criteria. As shown in Figs. 5(c) and 7, the predictions of delamination damage for all the interface layers of different models are within an acceptable range, where L6 and L7 interfaces present relatively larger deviations. This means the selection of the failure criterion in the finite element model affects the numerically calculated stress state, especially that for the back side of the laminate, which will then considerably influence the subsequent damage prediction. 


\subsubsection{Equivalent damage volume and energy dissipation}

Table 4 summarizes the total damage area of all damage modes, irrecoverable outof-plane displacement on the back side of laminate and dissipated energy of impactor that were obtained from simulation results using the five different failure criteria. Here, a newly-defined variable, the equivalent damage volume, is introduced and calculated by multiplying the total damage area $A_{d}$ and permanent displacement $U_{z}$ along the thickness direction. It can be found that the rank of the equivalent damage volume for each failure criterion is in accordance with that of dissipated energy, which suggests both the damage area and the permanent displacement of a laminate will determine its capability to absorb energy. Moreover, the introduction of equivalent damage volume introduces an alternative variable for quantitatively analyzing the low-velocity impact performance of composite laminates.

As shown in Table 4, the total predicted damage area of laminate using the maximum stress criterion is the smallest, resulting in the lowest amount of dissipated energy and equivalent damage volume. The Tsai-Wu criterion predicts the largest dissipated energy, and its prediction of permanent displacement is notably larger, which may be attributed to the subjective partitioning of tensile and compression damage in this study. The separation of tensile and compression damage can further affect the stiffness softening process and ultimately lead to a larger irreversible deformation. The limitation of the Tsai-Wu criterion is the lack of an effective way to realize the appropriate separation of tensile and compression damage, which is required for a progressive failure analysis in combination with damage evolution methods. On the 
other hand, the Hashin criterion predicts the largest area of damage, which can be attributed to its high prediction for the area of matrix compression damage. However, the dissipated energy predicted when using the Hashin criterion is comparatively less than for all other criteria, as the occurrence of matrix compression damage does not degrade the stiffness of the composite by much or significantly reduce the load-bearing capacity.

\subsection{Evaluation of damage evolution methods}

A damage evolution model is a necessary component for the modeling of progressive damage behavior in a composite structure. In this section, the maximum stress-based fiber damage criterion and Hou's matrix damage criterion are selected and implemented concurrently, along with two linear damage evolution methods (equivalent strain and equivalent displacement), so as to investigate the influence of the damage evolution method on the prediction of low-velocity impact behavior and the mode of failure for a composite laminate.

\subsubsection{Global mechanical response}

Fig. 8 compares the numerical predictions for mechanical responses using two different damage evolution models, the equivalent strain method and the equivalent displacement method. From Fig. 8, it can be noticed that the force-time and forcedisplacement curves predicted by the equivalent strain method show better correlation to the experimental data as compared to those of the equivalent displacement method. Evidently, as a consequence of controlling the stiffness degradation, the selection of damage evolution method has a more significant effect on the prediction of the global 
mechanical response than the change of failure criteria. However, quantitatively, the calculated dissipated energy of the impactor is similar for the two damage evolution models, which are $11.1 \mathrm{~J}$ and $11.3 \mathrm{~J}$ for the equivalent displacement method and equivalent strain method, respectively.

\subsubsection{Matrix and interface damage}

Fig. 9 presents a comparison of the predicted matrix tensile, matrix compression and delamination damage distributions of a laminate for models using the equivalent strain and equivalent displacement methods. This figure shows that the damage shapes and propagation directions for matrix tensile and delamination damage contours in each layer are similar, although a slight difference is observed for the lamina plies and interfaces near the impact side and back side of the panel. Only the top two plies are shown to illustrate the variation in the prediction of matrix compression damage. It is found that the predicted shapes of the matrix compression damage using the two different damage evolution models are altogether different for the first two layers (near the impact side), and no damage is predicted to occur in the second layer for the equivalent strain method. These results indicate that the selection of the damage evolution method has a greater effect on the damage distribution on the impact side and back side than on the shape of the matrix compression damage, which is similar to the effect for different failure criteria.

Fig. 10 shows the predicted matrix damage area and delamination area using the two different damage evolution methods. The equivalent displacement method is found to produce a larger area of damage than that obtained by the equivalent strain method, 
especially for the top and bottom layers of the laminate. The prediction of delamination area, as presented in Fig. 10(b), is similar for the two different damage evolution methods except for the bottom two interfaces, where obvious deviation can be seen.

\subsubsection{Damage accumulation process}

The effect of the damage evolution model on the damage accumulation process is investigated by comparing the damage variable profiles shown in Fig. 11. The damaged elements at the center of top and bottom surface, which can be found inside the boundaries of the grey rectangles in Fig. 11(b), are selected to present the time history for the matrix tensile and matrix compression damage variables for the interval from $t$ $=0 \mathrm{~ms}$ to $t=2 \mathrm{~ms}$. The value of matrix damage variables remains at one after $t=2 \mathrm{~ms}$, so the data for the interval from $t=2 \mathrm{~ms}$ to $t=4 \mathrm{~ms}$ is not shown. In the meantime, an irreversible operation is imposed on all damage variables to guarantee a continuous degradation of stiffness during the impact loading process.

As shown in Fig. 11(a), the matrix tensile damage variable $d_{m t}$ rises to the peak value more rapidly than the matrix compression damage variable $d_{m c}$. This is because tensile deformation is more significant than compressive deformation for the studied impact load of a composite laminate. Consequently, matrix tensile damage is easier to generate, and it propagates faster than matrix compression damage. Moreover, elements typically lose their ability to bear transverse tensile loading immediately after being detected with matrix tensile damage during an impact, which contributes to a sudden growth of $d_{m t}$ from 0 to 1 for both the equivalent displacement method and the equivalent strain method. In addition, it is obvious that the compressive damage to the 
matrix at the impact point initiates earlier when using the equivalent displacement method, which predicts an earlier increase of the $d_{m c}$ profile, since the equivalent strain method disregards the shear strain components. Moreover, the $d_{m c}$ profile of the equivalent strain method shows a much sharper increase from 0 to 1 than that of the equivalent displacement method.

Fig. 11(b) shows the evolution in the morphology of the matrix compression damage $\left(d_{m c}\right)$ in the top layer for two evolution methods. For the equivalent displacement method, damage initiates at the center and propagates gradually in a butterfly shape; for the equivalent strain method, the matrix compression damage first increases sharply around the point of impact and then expands through the central area. Therefore, it can be concluded that element suffers a much faster stiffness degradation after damage initiation when the equivalent strain method is selected.

\section{Conclusions}

Different failure criteria and damage evolution methods are integrated into the finite element simulations for low-velocity impact behavior of a T700GC/M21 carbon/epoxy composite laminate. The variation of global mechanical response represented by the force-time curve, the force-displacement curve, energy dissipation, and local damage in each ply are investigated in detail. The applicability of different failure criteria and damage accumulation methods for predicting the low-velocity impact damage of laminates is discussed. The main conclusions are summarized as follows:

- All selected failure criteria are adequate for predicting the global mechanical 
response. The failure criteria that show less error in the prediction of dissipation energy usually tend to produce larger derivations in the prediction of peak force, maximum displacement, and impact contact time compared with experimental test data.

- The predicted matrix tensile damage by all failure criteria show a similar propagation direction and damage shape, except for that of the Hashin criterion, which produces a hollowing effect. The deviation of the predicted damaged area is the most significant for the top and bottom layers of the laminate.

- Matrix compression damage distributions predicted by different failure criteria are totally different in terms of damage shape, area and propagation distribution. Hashin's matrix compression criterion could be a good choice for engineering applications due to its conservative prediction and simple expression.

- Maximum stress and Tsai-Wu failure criteria are not recommended for use in a low-velocity impact simulation. The predicted total damage area using the maximum stress criterion is the lowest since this criterion disregards the shear stress components. The Tsai-Wu criterion shows the greatest irreversible displacement due to improper separation of tensile and compression damage.

- Damage evolution methods display a more significant influence on the prediction of the global mechanical response. For local damage prediction, the matrix damage area is larger when using the equivalent displacement method, while the equivalent strain method corresponds to a more rapid reduction in stiffness.

- Both the failure criteria and damage evolution methods have little effect on the 
prediction of delamination damage.

\section{Acknowledgements}

This work is supported by National Science Foundation of China (NSFC) under grant number 11772267 and 11372256.

\section{References}

[1] Sleight D W. Progressive Failure Analysis Methodology for Laminated Composite Structures. NASA Langley Technical Report Server, 1999.

[2] Tay TE, Liu G, Tan VB, Sun XS, Pham DC. Progressive failure analysis of composites. Journal of Composite Materials. 2008;42(18):1921-66.

[3] Liu P F, Zheng J Y. Recent developments on damage modeling and finite element analysis for composite laminates: A review. Materials \& Design, 2010; 31(8):38253834.

[4] Faggiani A, Falzon B G. Predicting low-velocity impact damage on a stiffened composite panel. Composites Part A Applied Science \& Manufacturing, 2010; 41(6):737-749.

[5] Hongkarnjanakul N, Bouvet C, Rivallant S. Validation of low velocity impact modelling on different stacking sequences of CFRP laminates and influence of fibre failure. Composite Structures, 2013; 106(12):549-559.

[6] Tan W, Falzon BG, Chiu LN, Price M. Predicting low velocity impact damage and Compression-After-Impact (CAI) behaviour of composite laminates. Composites Part A: Applied Science and Manufacturing. 2015;71:212-26. 
[7] Abir MR, Tay TE, Ridha M, Lee HP. Modelling damage growth in composites subjected to impact and compression after impact. Composite Structures. 2017;168:13-25.

[8] Tsai S W, Wu E M. A General Theory of Strength for Anisotropic Materials. Journal of Composite Materials, 1971; 5(1):58-80.

[9] Hashin, Z, Rotem, A. A Fatigue Failure Criterion for Fiber Reinforced Materials. Journal of Composite Materials, 1973; 7(4):448-464.

[10]Chang F K, Chang K Y. A Progressive Damage Model for Laminated Composites Containing Stress Concentrations. Journal of Composite Materials, 1987; 21(9):834-855.

[11]Hou JP, Petrinic N, Ruiz C, Hallett SR. Prediction of impact damage in composite plates. Composites Science and Technology. 2000;60(2):273-81. [12].

[12]Hou JP, Petrinic N, Ruiz C. A delamination criterion for laminated composites under low-velocity impact. Composites science and technology. 2001;61(14):206974.

[13]Puck A, Schürmann H. Failure analysis of FRP laminates by means of physically based phenomenological models. Composites Science \& Technology, 2002;62(1213):1633-1662.

[14]Kim JH, Pierron F, Wisnom MR, Avril S. Local stiffness reduction in impacted composite plates from full-field measurements. Composites Part A: Applied Science and Manufacturing. 2009;40(12):1961-74.

[15]Devivier C, Pierron F, Wisnom M R. Damage detection in composite materials 
using deflectometry, a full-field slope measurement technique. Composites Part A, 2012; 43(10):1650-1666.

[16] Gu X, Pierron F. Towards the design of a new standard for composite stiffness identification. Composites Part A, 2016;91:448-460.

[17]Zhao Z, Dang H, Zhang C, Yun GJ, Li Y. A multi-scale modeling framework for impact damage simulation of triaxially braided composites. Composites Part A: Applied Science and Manufacturing. 2018;110:113-25.

[18]Long S, Yao X, Zhang X. Delamination prediction in composite laminates under low-velocity impact. Composite Structures, 2015;132:290-298.

[19] Shi Y, Swait T, Soutis C. Modelling damage evolution in composite laminates subjected to low velocity impact. Composite Structures, 2012;94(9):2902-2913.

[20]Qiu A, Fu K, Lin W, Zhao C, Tang Y. Modelling low-speed drop-weight impact on composite laminates. Materials \& Design. 2014;60:520-31.

[21]Zhang C, Duodu EA, Gu J. Finite element modeling of damage development in cross-ply composite laminates subjected to low velocity impact. Composite Structures. 2017;173:219-27.

[22] Caputo F, De Luca A, Lamanna G, Borrelli R, Mercurio U. Numerical study for the structural analysis of composite laminates subjected to low velocity impact. Composites Part B: Engineering. 2014;67:296-302.

[23]Zhang J, Zhang X. An efficient approach for predicting low-velocity impact force and damage in composite laminates. Composite Structures, 2015;130:85-94.

[24]Hinton MJ, Kaddour AS, Soden PD. Failure criteria in fibre reinforced polymer 
composites: the world-wide failure exercise. Elsevier; 2004.

[25]Kaddour AS, Hinton MJ. Maturity of 3D failure criteria for fibre-reinforced composites: Comparison between theories and experiments: Part B of WWFE-II. Journal of Composite materials. 2013;47(6-7):925-66.

[26]Kaddour AS, Hinton MJ, Smith PA, Li S. A comparison between the predictive capability of matrix cracking, damage and failure criteria for fibre reinforced composite laminates: Part A of the third world-wide failure exercise. Journal of Composite Materials. 2013;47(20-21):2749-79.

[27]Reddy Y S, Reddy J N. Three-dimensional finite element progressive failure analysis of composite laminates under axial extension. 1993; 15(2):73-87.

[28] Santiuste C, Sánchez-Sáez S, Barbero E. A comparison of progressive-failure criteria in the prediction of the dynamic bending failure of composite laminated beams. Composite Structures, 2010; 92(10):2406-2414.

[29] Liu PF, Liao BB, Jia LY, Peng XQ. Finite element analysis of dynamic progressive failure of carbon fiber composite laminates under low velocity impact. Composite Structures. 2016;149:408-22.

[30]Farooq U, Myler P. Finite element simulation of damage and failure predictions of relatively thick carbon fibre-reinforced laminated composite panels subjected to flat and round noses low velocity drop-weight impact. Thin-Walled Structures, 2016;104:82-105.

[31]Lee CS, Kim JH, Kim SK, Ryu DM, Lee JM. Initial and progressive failure analyses for composite laminates using Puck failure criterion and damage-coupled 
finite element method. Composite Structures. 2015;121:406-19.

[32]Donadon MV, Iannucci L, Falzon BG, Hodgkinson JM, de Almeida SF. A progressive failure model for composite laminates subjected to low velocity impact damage. Computers \& Structures. 2008;86(11-12):1232-52.

[33]Zhang C, Li N, Wang W, Binienda WK, Fang H. Progressive damage simulation of triaxially braided composite using a 3D meso-scale finite element model. Composite Structures. 2015;125:104-16.

[34]Benzeggagh M L, Kenane M. Measurement of mixed-mode delamination fracture toughness of unidirectional glass/epoxy composites with mixed-mode bending apparatus. Composites Science \& Technology, 1996;56(4):439-449.

[35]Lou X, Cai H, Yu P, Jiao F, Han X. Failure analysis of composite laminate under low-velocity impact based on micromechanics of failure. Composite Structures. 2017;163:238-47.

[36] Abrate S, Castanié B, Rajapakse YD. Dynamic failure of composite and sandwich structures. Springer Science \& Business Media; 2012. 


\section{Figures}

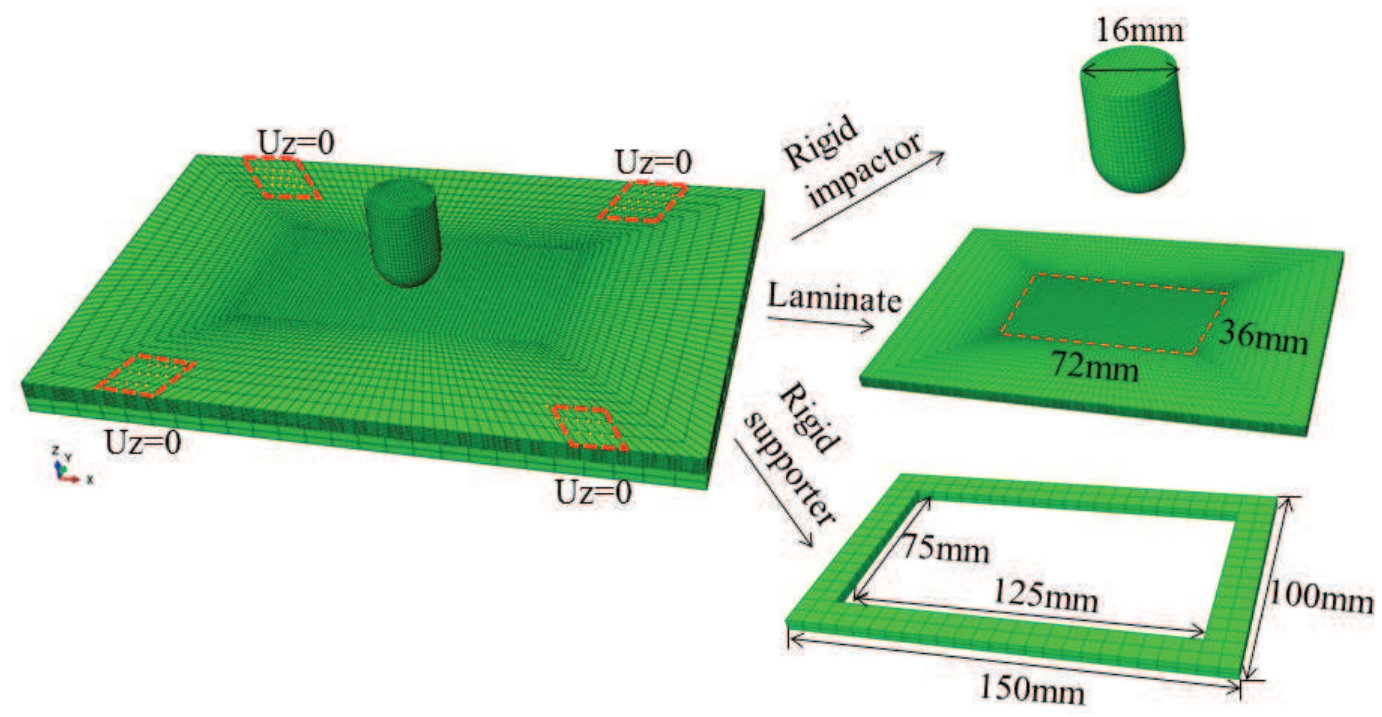

Fig. 1. Finite element model for low-velocity impact analysis.
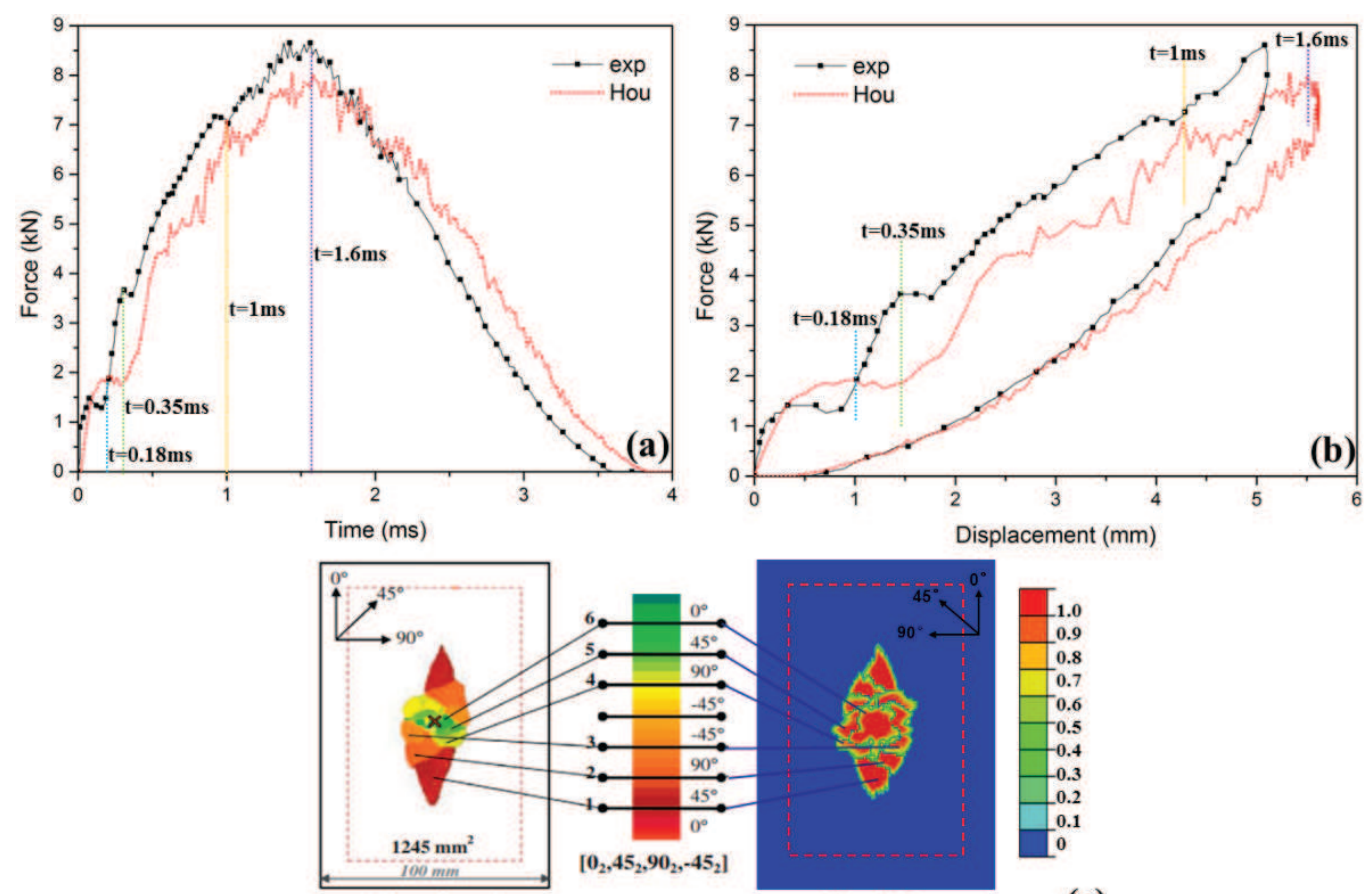

Simulation

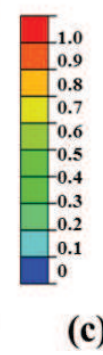

Fig. 2. Comparisons between experimental and numerical results: (a) Contact force versus time history, (b) Contact force versus displacement history, (c) Overlapped delamination area (reproduced from experimental C-scan results presented in Fig. 4 in Ref. [5]). 

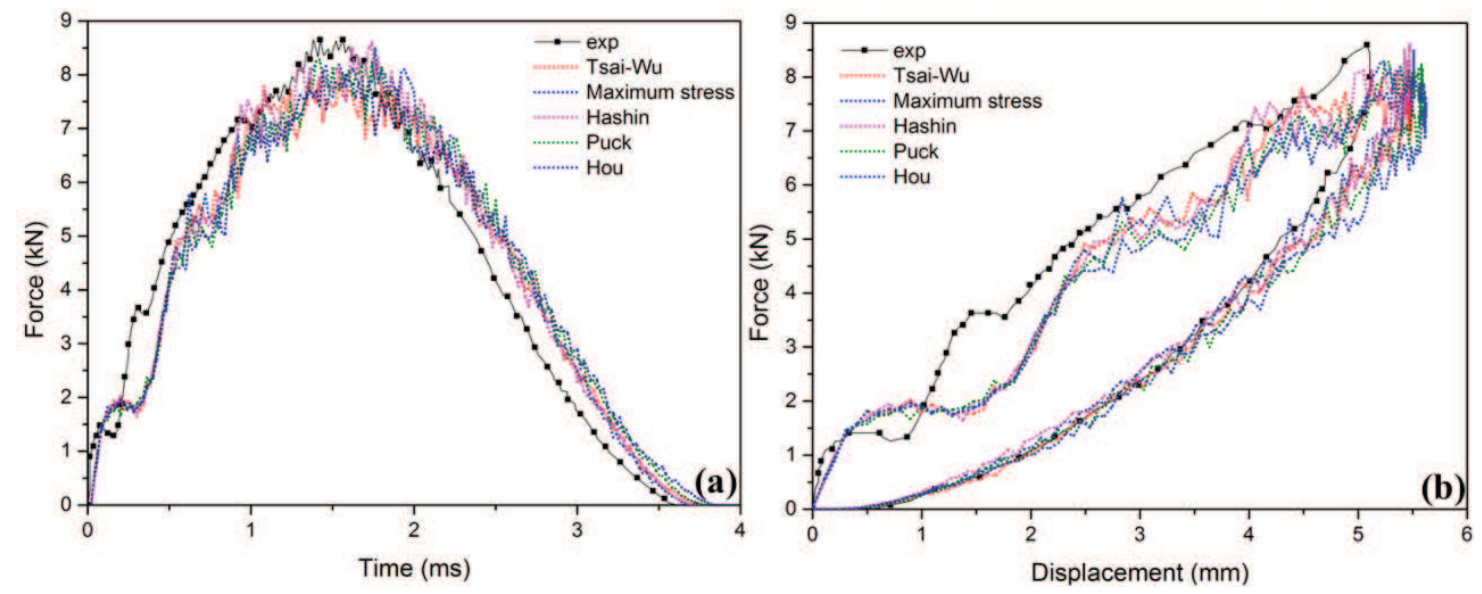

Fig. 3. Comparison of predicted global responses using models with different failure

criteria and the same equivalent displacement based damage evolution law: (a) Force

versus time history and (b) Force versus displacement history.

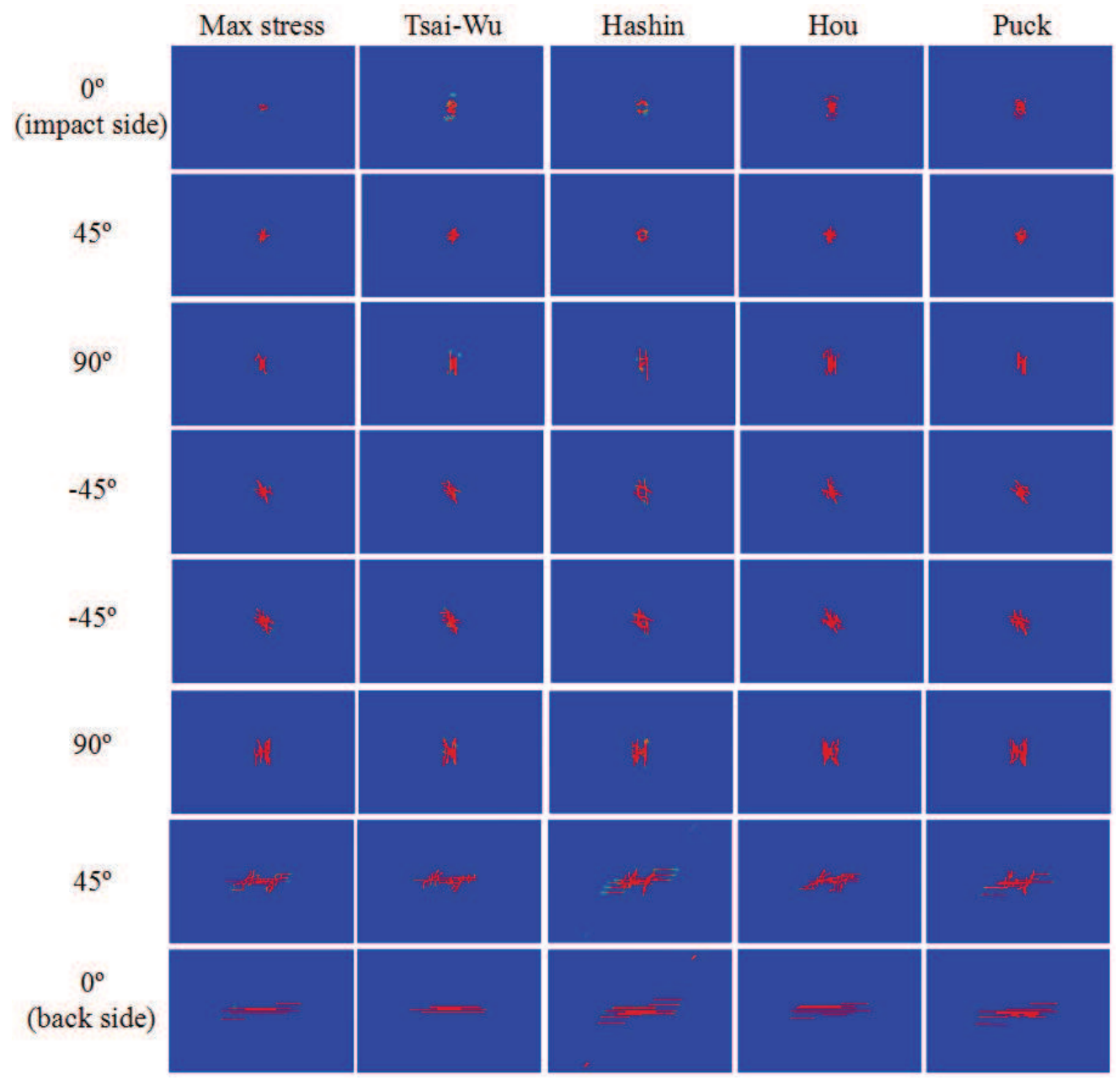

Fig. 4. Comparison of predicted matrix tensile damage in each ply of the laminate for models with different failure criteria. 

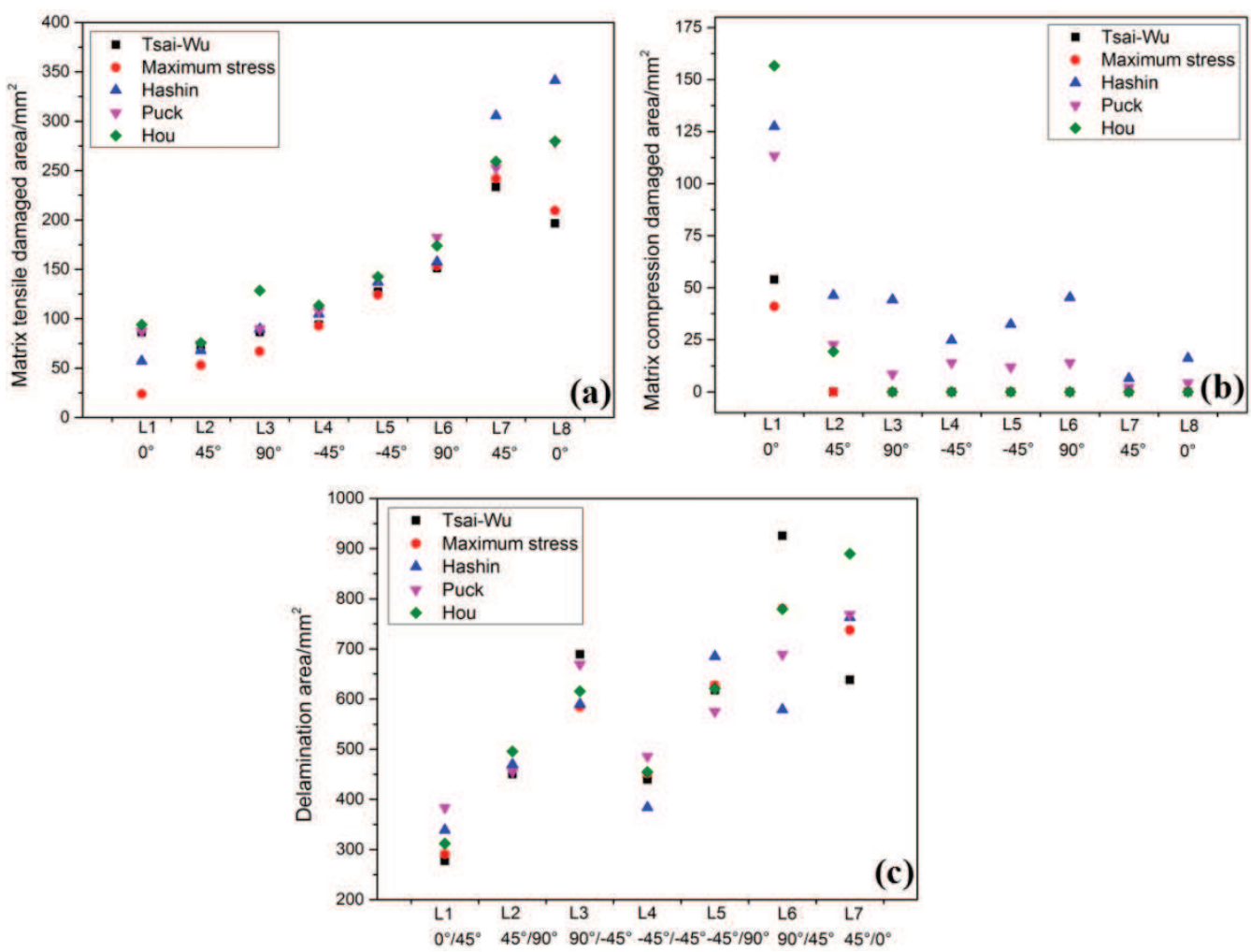

Fig. 5. Comparison of predicted damage area for each layer of the composite laminate for models with different failure criteria: (a) Matrix tensile damage area, (b) Matrix compression damage area, (c) Delamination damage area.

(a)

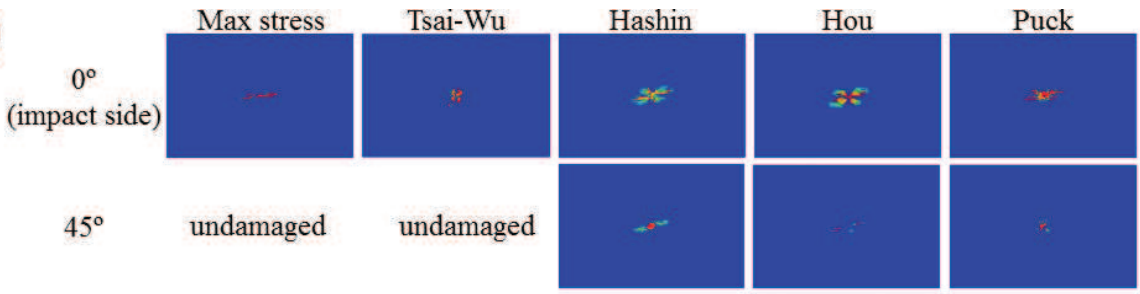

(b)

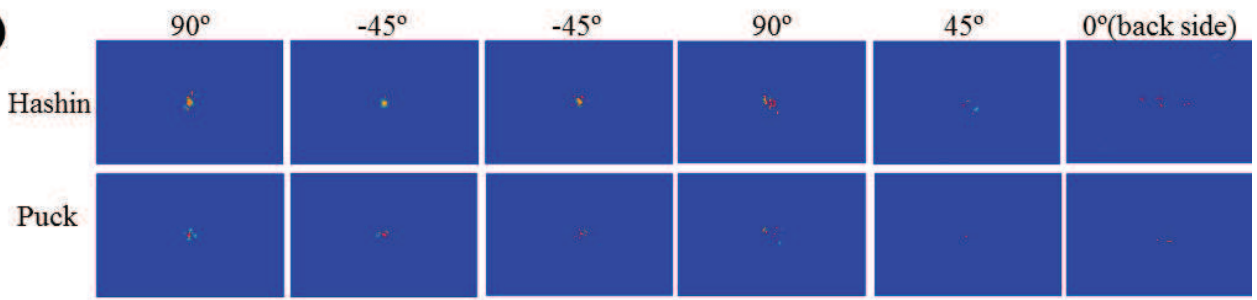

Fig. 6. Comparison of predicted matrix compression damage for each ply of the composite laminate for models with different failure criteria: (a) Damage on the top two layers and (b) Damage on the remaining layers. 


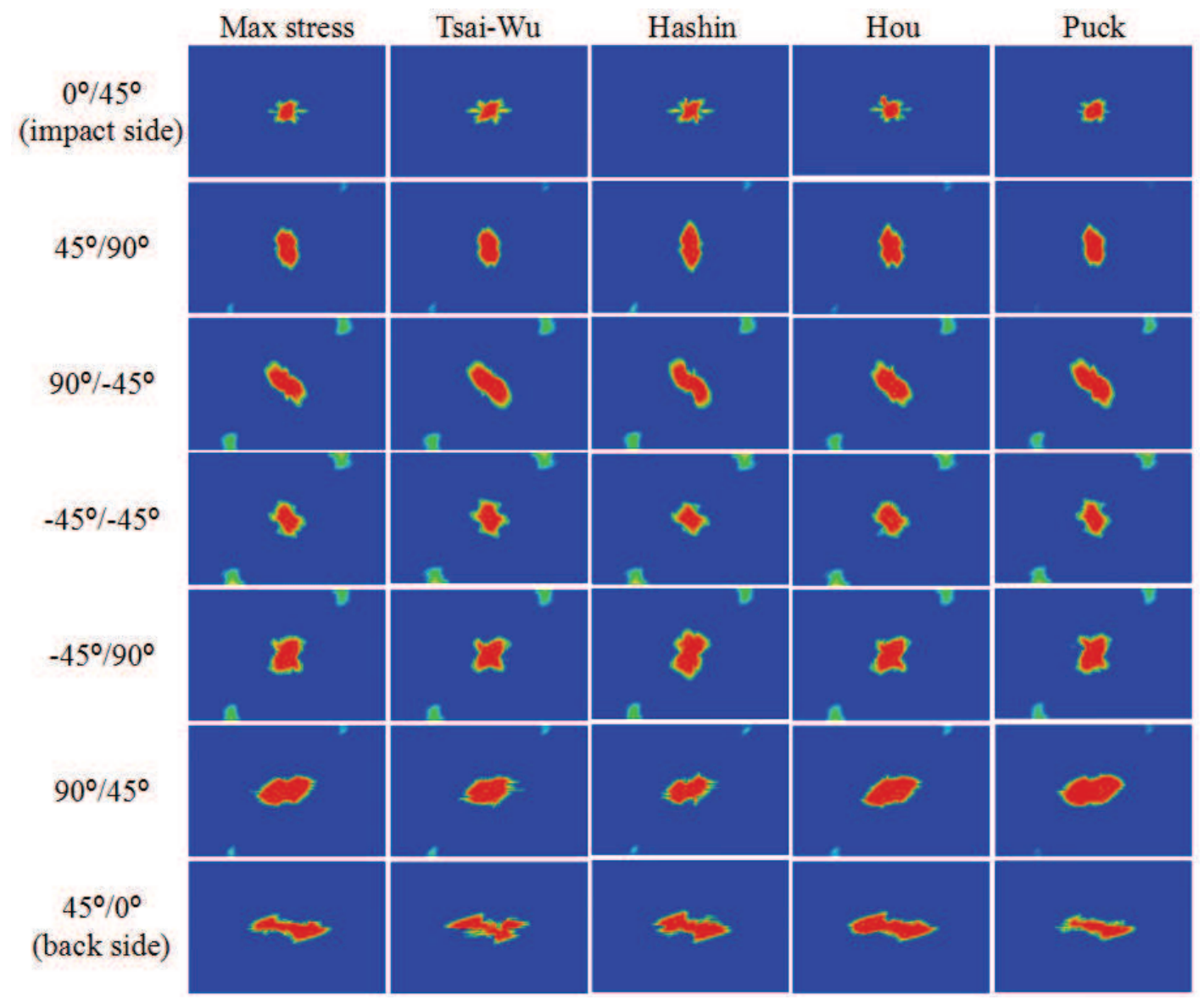

Fig. 7. Comparison of predicted delamination damage in each interface of the laminate for models with different failure criteria.
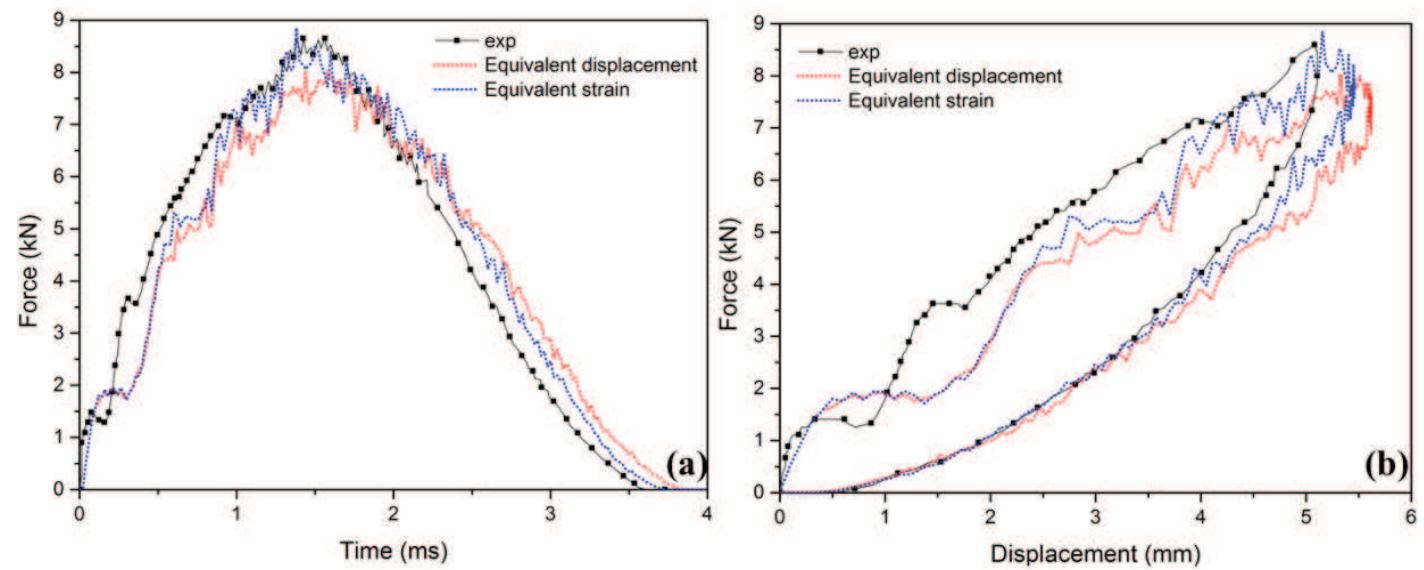

Fig. 8. Comparison of numerical predicted mechanical responses by models with

different damage evolution methods: (a) Force versus time curve and (b) Force versus displacement curve. 


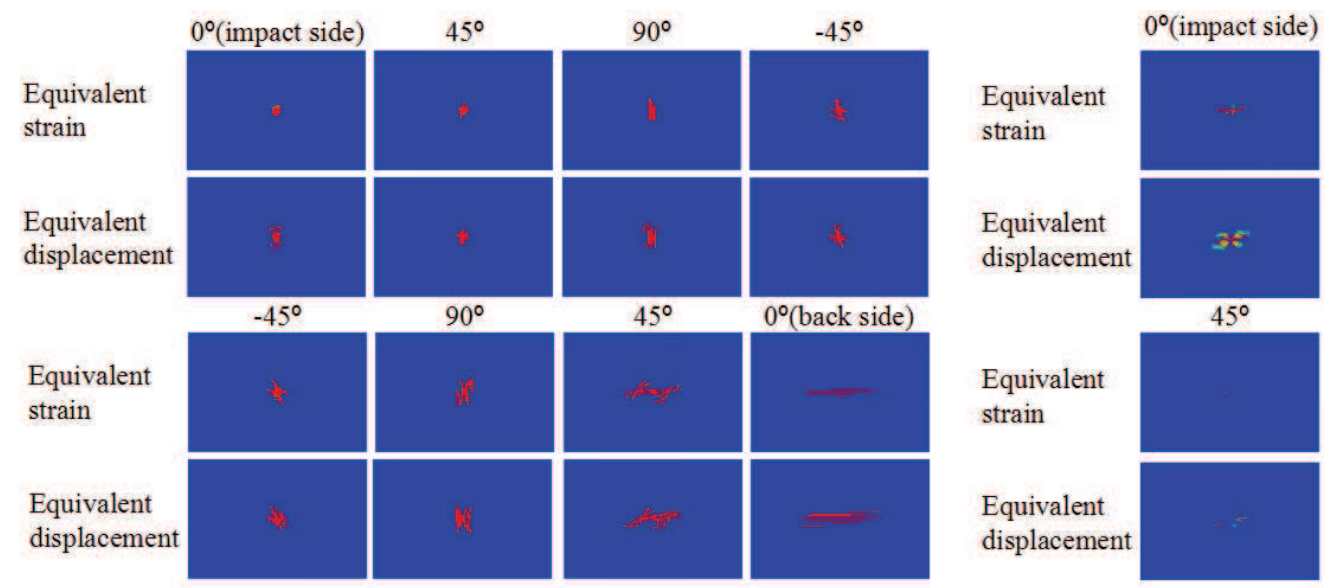

(a) Matrix tensile damage

(b)Matrix compression damage

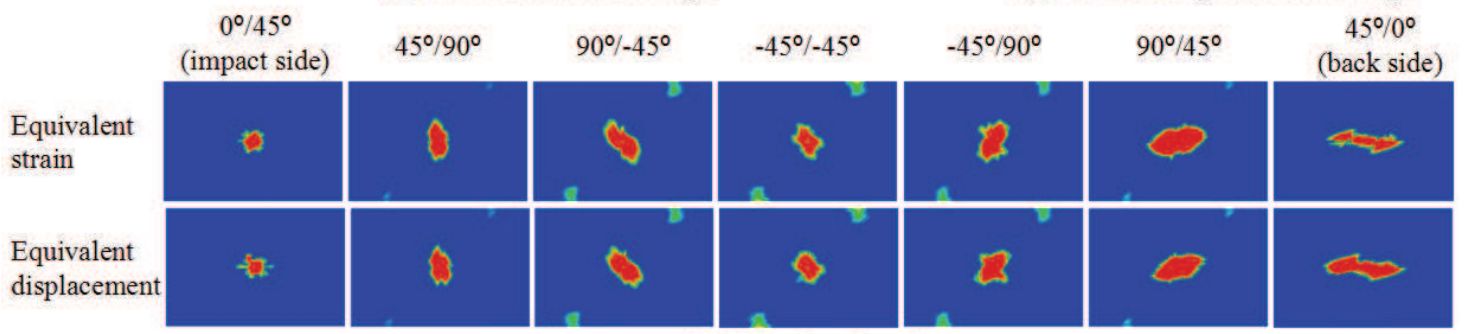

(c) Delamination damage

Fig. 9. Predicted matrix damage in each ply and delamination damage in each

interface of laminate by using two different damage evolution methods.
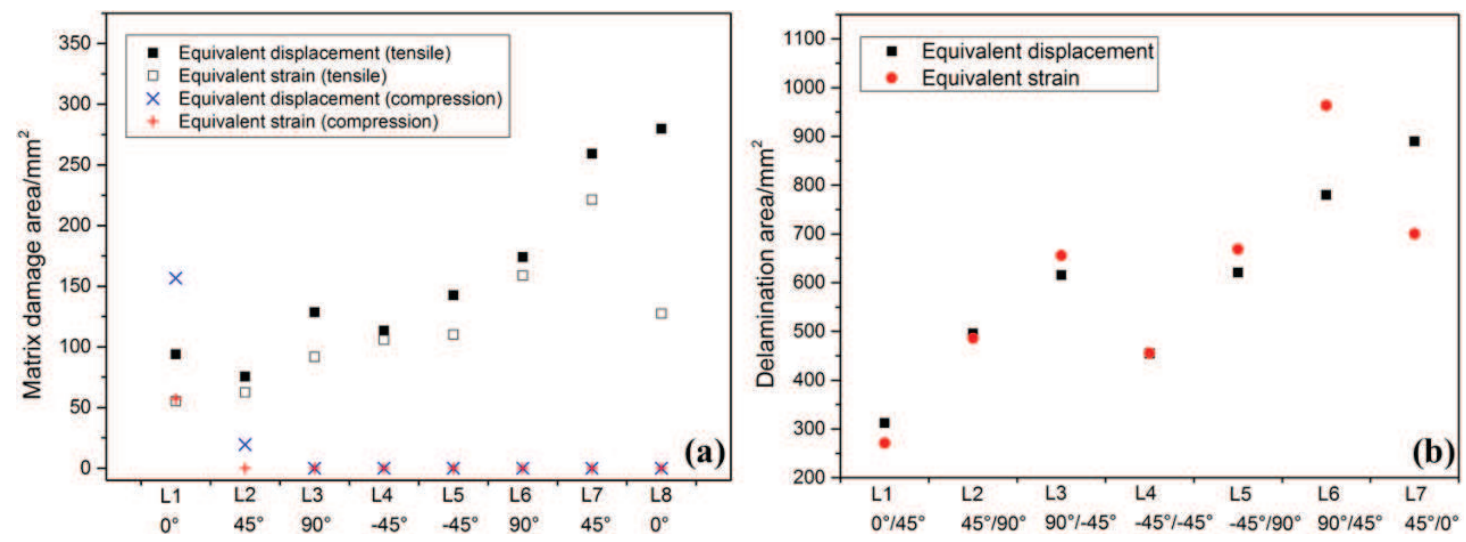

Fig. 10. Predicted damaged area in each ply or interface using two different damage

evolution methods: (a) Matrix tensile and compression damage area, and (b)

Delamination damage area. 


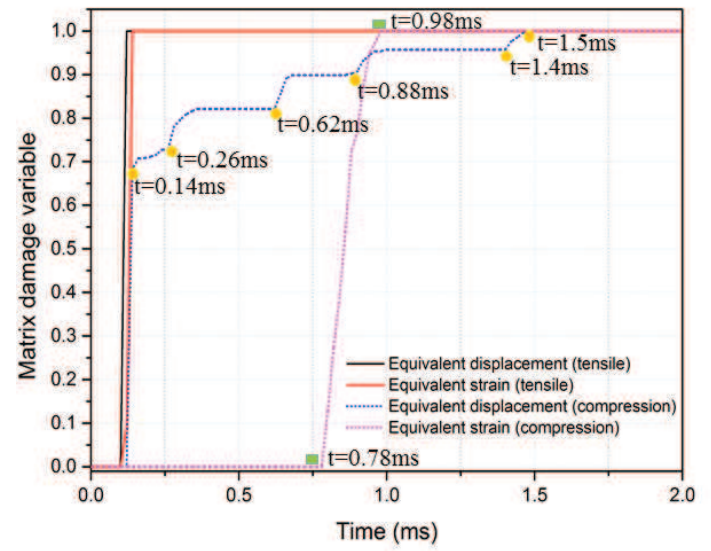

(a) Matrix damage variable versus time history

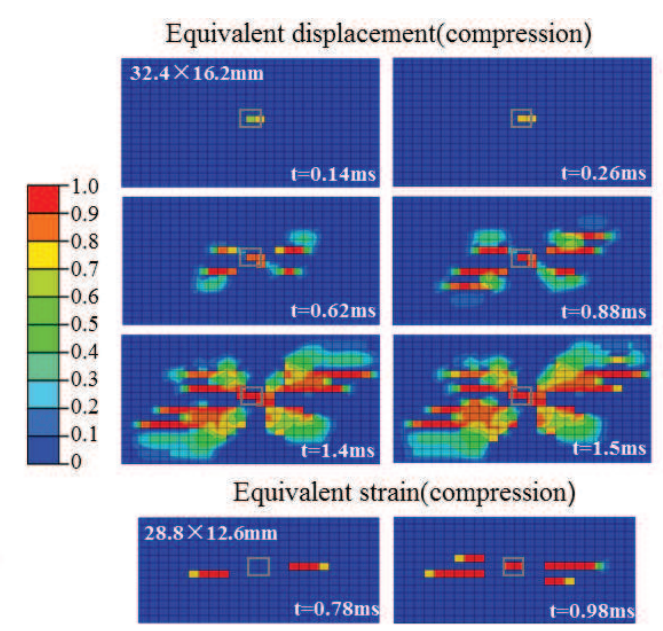

(b) Matrix compression damage distribution on the impact side

Fig. 11. Comparison of matrix damage variable profile (obtained from element at the center of back side for tensile damage, element at the center of impact side for compression damage) and matrix compression damage contours for models with different damage evolution methods. 


\section{Tables}

Table 1. Characteristics for five different failure criteria

\begin{tabular}{lccccc}
\hline Failure criteria & Max stress & Tsai-Wu & Hashin & Puck & Hou \\
\hline Separated damage modes & $\mathrm{Y}$ & $\mathrm{N}$ & $\mathrm{Y}$ & $\mathrm{Y}$ & $\mathrm{Y}$ \\
Shear stress components & $\mathrm{N}$ & $\mathrm{Y}$ & $\mathrm{Y}$ & $\mathrm{Y}$ & $\mathrm{Y}$ \\
Fracture plane & $\mathrm{N}$ & $\mathrm{N}$ & $\mathrm{N}$ & $\mathrm{Y}$ & $\mathrm{N}$ \\
Tensile \& compression judgment & $\sigma_{22}$ & $\sigma_{22}$ & $\sigma_{22}+\sigma_{33}$ & $\sigma_{22}$ & $\sigma_{22}$ \\
\hline
\end{tabular}

Note: "Y" denotes "include" and "N" denotes "exclude".

Table 2. Material properties for T700GC/M21 composite laminates

\begin{tabular}{lll}
\hline & Density & $\rho=1600 \mathrm{~kg} / \mathrm{m}^{3}$ \\
& Young's modulus & $E_{11}=130 \mathrm{GPa}, E_{22}=E_{33}=7.7 \mathrm{GPa}$, \\
& & $G_{23}=3.8 \mathrm{GPa}, G_{12}=G_{13}=4.8 \mathrm{GPa}$ \\
Composite & Poisson's ratio & $v_{23}=0.35, v_{12}=v_{13}=0.33$ \\
lamina & & $X_{T}=2080 \mathrm{MPa}, X_{\mathrm{C}}=1250 \mathrm{MPa}, Y_{T}=60$ \\
properties & Strength & $\mathrm{MPa}$ \\
& & $Y_{\mathrm{C}}=140 \mathrm{MPa}, S_{12}=S_{13}=S_{23}=110 \mathrm{MPa}$ \\
& & $G_{f t}=133 \mathrm{~N} / \mathrm{mm}, G_{f c}=40 \mathrm{~N} / \mathrm{mm}$, \\
& Fracture energy & $G_{m t}=0.6 \mathrm{~N} / \mathrm{mm}, G_{m c}=2.1 \mathrm{~N} / \mathrm{mm}$ \\
\hline \multirow{2}{*}{ Interface } & Modulus & $E=5 \mathrm{GPa}$ \\
properties & Strength & $N=S=30 \mathrm{MPa}$ \\
& Fracture energy & $G C n=0.6 \mathrm{~N} / \mathrm{mm}, G C s=2.1 \mathrm{~N} / \mathrm{mm}$ \\
\hline
\end{tabular}

Note: Properties were obtained from tests conducted by Hongkarnjanakul et al. [5]. 
Table 3. Experimental and numerical parameters reflecting global response of the laminate during an impact load

\begin{tabular}{ccccc}
\hline & $\begin{array}{c}\text { Peak force } \\
(\mathrm{kN})\end{array}$ & $\begin{array}{c}\text { Max. displacement } \\
(\mathrm{mm})\end{array}$ & $\begin{array}{c}\text { Impact time } \\
(\mathrm{ms})\end{array}$ & $\begin{array}{c}\text { Dissipated } \\
\text { energy }(\mathrm{J})\end{array}$ \\
\hline Test data & 8.65 & 5.11 & 3.6 & 13.2 \\
Max. & & & $3.72(+3.3 \%)$ & $10.0(-24.24 \%)$ \\
stress & $8.49(-1.85 \%)$ & $5.51(+7.83 \%)$ & & $11.3(-14.39 \%)$ \\
Tsai-Wu & $8.1(-6.79 \%)$ & $5.49(+7.44 \%)$ & $3.8(+5.6 \%)$ & $10.4(-21.21 \%)$ \\
Hashin & $8.6(-0.58 \%)$ & $5.47(+7.05 \%)$ & $3.72(+3.3 \%)$ & $11.1(-15.9 \%)$ \\
Hou & $8.03(-7.2 \%)$ & $5.62(+9.98 \%)$ & $3.86(+7.2 \%)$ & $10.62(-19.55 \%)$ \\
Puck & $8.27(-4.39 \%)$ & $5.59(+9.39 \%)$ & $3.8(+5.6 \%)$ & \\
\hline
\end{tabular}

Note: Test data was obtained from Hongkarnjanakul et al. [5].

Table 4. Summary of total damage area, permanent out-of-plane displacement and equivalent damage volume, and dissipated energy of composite laminate after a lowvelocity impact

\begin{tabular}{ccccccc}
\hline Failure criterion & $\begin{array}{c}\text { Test } \\
\text { data }\end{array}$ & $\begin{array}{c}\text { Max. } \\
\text { Stress }\end{array}$ & $\begin{array}{c}\text { Tsai- } \\
\mathrm{Wu}\end{array}$ & Hashin & Hou & Puck \\
\hline $\begin{array}{c}\text { Total damage area } \\
A_{d}\left(\mathrm{~mm}^{2}\right)\end{array}$ & N/A & 4919 & 5138 & 5720 & 5612 & 5435 \\
$\begin{array}{c}\text { Permanent } \\
\text { displacement } \\
U_{z}(\mathrm{~mm})\end{array}$ & 0.5244 & 0.4791 & 0.6585 & 0.4281 & 0.4843 & 0.4560 \\
$\begin{array}{c}\text { Equivalent damage } \\
\text { volume }\end{array}$ & N/A & 2357 & 3383 & 2449 & 2718 & 2478 \\
$\begin{array}{c}\left.A_{d} \times U_{z}(\mathrm{~mm})^{3}\right) \\
\text { Dissipated energy }\end{array}$ & & & & & & \\
$(\mathrm{J})$ & 13.0 & 10.0 & 11.3 & 10.4 & 11.1 & 10.6 \\
\hline
\end{tabular}

Note: Test data was obtained from Hongkarnjanakul et al. [5]. 